\title{
Resenhas
}

\section{Entre o pessimismo da razão e o otimismo da vontade}

LÖWY, Michael.

(2004) A jaula de aço: Max Weber e o marxismo weberiano. Tradução de Mariana Echalar.

São Paulo: Boitempo Editorial. 144 p. ISBN 978-85-7559-401-8.

Publicado no Brasil pela editora Boitempo em 2014, A jaula de aç, do cientista social Michael Löwy, corrobora relacionar duas correntes sociológicas weberianismo e marxismo - vistas como defensoras de proposições opostas, consequentemente, impossíveis de serem alocadas de forma amistosa na formulação de um quadro conceitual ou mesmo teórico-metodológico, mas que, segundo o autor, guardam convergências entre si.

De ascendência judaica, Michael Löwy nasceu em 1938 no Brasil, formouse em Ciências Sociais pela Universidade de São Paulo em 1960, doutorandose sob orientação de Lucien Goldmann, em 1964, pela Sorbonne. Atualmente, reside na França e é diretor de pesquisa no Centre National de la Recherche Scientifique. Löwy tem expressiva bibliografia sobre a história do pensamento de esquerda, desenvolvendo trabalhos sobre Karl Marx, György Lukács, Lucien Goldmann e Walter Benjamin. Nesse sentido, o presente livro, o qual resenhamos, é instigante, uma vez que propõe pensar os usos da sociologia de Max Weber - um autor liberal - por autores reconhecidamente marxistas, formando, assim, uma "corrente" sociológica referida como webero-marxista.

A primeira parte do livro "Weber, Marx e a "jaula de aço" é composta por dois capítulos, no primeiro: "Marx e Weber: Kapitalismus”, Löwy discute as divergências entre Weber e Marx, tais diferenças seriam essencialmente políticas e metodológicas, no entanto, os dois autores teriam em suas obras questões afins, a começar pelo interesse que ambos tinham pelo capitalismo, ademais, os dois pensadores estariam de acordo entre pontos fundamentais, tais quais a definição de classes sociais por suas posições de poder e propriedade, o Estado racional e burocrático como uma das condições de existência necessárias para o estabelecimento do capitalismo e, também, o monopólio estatal sobre a violência.

Sobre as origens do capitalismo, Löwy explicita a teses dos dois autores. Para Marx, a explicação estaria posta no conceito de acumulação primitiva, isto é, a expropriação dos camponeses pelos cercamentos, o escravagismo e a 
exploração colonial. Para Weber, grosso modo, o capitalismo moderno seria produto de empreendedores movidos pela ética protestante.

Löwy chama a atenção para a necessidade de salientar que Weber não desconsideraria as formas do capital voltadas para a violência, denominandoas capitalismo imperialista ou aventureiro. Ou seja, Weber priorizaria aspectos socioculturais - em uma interpretação "espiritualista" da história - enquanto Marx evidenciaria os aspectos materiais - fruto teórico-metodológico do materialismo histórico.

Embora seja evidente o contraste entre as duas perspectivas, o autor da jaula de aço chama a atenção para os fragmentos da obra de Weber que deixa clara a sua preocupação em não apresentar suas conclusões acerca do capitalismo como causas decorrentes de fatores culturais apenas, chamando atenção, inclusive, para a necessidade de se estudar a contribuição dos fatores econômicos que levaram ao surgimento e ao estabelecimento do capitalismo.

Como afirma Löwy, Weber, embora não fosse um marxista, estava longe de ser um antimaterialista, deixando de forma implícita em algumas passagens de sua obra seu reconhecimento acerca da primazia das transformações econômicas sobre as transformações socioculturais, embora, com isso, não buscasse uma interpretação de base material, e sim congruente entre tais esferas, a material e a cultural, nesse sentido, Weber trabalha o termo "afinidade eletiva".

Outro ponto comum, evidenciado por Löwy, possível de ser pensado nas obras de Marx e Weber, diz respeito à crítica ao capitalismo, os dois autores perceberiam o sistema capitalista através de um prisma fundamentalmente negativo, em que a quantificação da vida social, a exploração do trabalho, a desigualdade das riquezas, a reificação e a submissão ao mercado seriam imperativos.

Karl Marx, ao longo de suas obras, desenvolveria uma crítica anticapitalista baseada na necessidade e na inevitabilidade de transformação do sistema para um estágio pós-capitalista. Já em Max Weber, a crítica seria mais ambígua, uma vez que o autor, segundo Löwy, não veria horizonte além do capitalismo, pois seria este o sistema mais racional de desenvolvimento possível. No entanto, Weber chama a atenção para o fato de que a intensa e voraz busca pela eficácia do sistema levaria a uma intensa burocratização e coisificação das atividades humanas. Enfim, a diferença estaria no pensamento pessimista de Weber diante das ideias revolucionárias do autor de $O$ Capital.

A visão pessimista de Weber é objeto do segundo capítulo de A jaula de aço, intitulado "O pessimismo cultural de Max Weber". Nele, o autor chama 
a atenção para a ênfase dada por Weber à negação de qualquer possibilidade de progresso a partir do estágio capitalista, o que faz do autor de Economia e Sociedade um "pessimista resignado", nas palavras de Löwy. A partir dessa premissa, Weber cunharia o termo "habitáculo de aço" ou "jaula de aço", pois o capitalismo moderno levaria os indivíduos a uma espécie de escravidão sem mestre, uma vez que todos estavam subordinados a regras cotidianas impostas tacitamente pelo sistema e que seriam absolutas e impessoais. Para Weber, o sistema capitalista não comungava com a liberdade, pelo contrário, cada vez mais a sociedade deveria seguir os imperativos do mercado, a questão a ser posta era como valores, tais quais os de liberdade e democracia, seriam possíveis com o desenvolvimento do sistema no decorrer do tempo?

A segunda parte do livro, "Max Weber sobre as afinidades eletivas", é composta de dois capítulos: "o conceito de afinidade eletiva", o terceiro capítulo do livro; e "A ética católica e o espírito do capitalismo: afinidade negativa", o quarto capítulo da obra. Neles, Löwy traça a relação feita por Weber entre as condições culturais, isto é, a ética protestante e as condições materiais que levaram à formação do capitalismo.

Nesse sentido, Weber trabalha o conceito de "afinidade eletiva". Como já dito, haveria uma congruência entre aspectos de caráter material com aspectos de caráter "espiritual" que possibilitariam o surgimento e a consolidação do sistema capitalismo. Posto isso, Löwy trabalha a percepção de Weber sobre o catolicismo; embora o autor alemão nunca tenha se debruçado sobre o catolicismo, seria possível identificar, ao longo de sua obra, a sua percepção acerca dessa religião, segundo a qual a ética católica teria uma profunda antipatia pelo capitalismo, devido a sua impessoalidade nas relações entre os indivíduos, o que impediria o catolicismo de regulá-lo. Essa crítica, segundo Weber, teria um caráter reacionário, visto que, por exemplo, no decorrer do feudalismo, o papel da Igreja na regulação de certas relações era uma constante.

A partir do final do século XIX, surge na Europa uma crítica não reacionária ao capitalismo, segundo Löwy, uma crítica católica de esquerda, que na América latina aparece em meados do século XX - a Teologia da Libertação. A leitura de Weber, mesmo escrevendo de um passado consideravelmente distante, ajudaria a entender tais fenômenos no entender de Löwy.

Na terceira e última parte do livro, "Marxismo Weberiano", Michael Löwy discute em dois capítulos os usos de Weber por pensadores reconhecidamente marxistas. No quinto capítulo, "O capitalismo como religião: Ernst Bloch, Walter Benjamin e Erich Fromm, leitores de Max Weber", autores que 
fizeram leituras anticapitalistas das obras de Weber são discutidos, embora não fossem marxistas weberianos propriamente ditos.

O primeiro autor evocado é Ernst Bloch, que, pautado em Weber, teria inventado o termo "capitalismo como religião" e estabelecido uma crítica ao calvinismo por ter, segundo ele, destruído o cristianismo e levantado um culto ao dinheiro. O segundo autor trazido à baila é Walter Benjamin, que desenvolve a ideia do "capitalismo como religião" a partir das conclusões de Weber, acerca da íntima relação entre a ética protestante e o sistema capitalista. No entanto, Benjamin iria mais adiante no pensamento, ao afirmar que, mais do que ter surgido a partir de um fenômeno religioso, o capitalismo era em si um fenômeno religioso. Por fim, Löwy expõe o pensamento de Fromm, segundo o qual o capitalismo, seguindo as premissas éticas do calvinismo, transformou o meio para a felicidade em um fim, ou seja, o trabalho passa a ser mais importante do que a possibilidade de aquisição advinda através dele. Esta perspectiva, tal qual a dos dois pensadores anteriormente citados, teria sido embasada na obra de Weber.

No último capítulo do livro, "figuras do marxismo weberiano: de Lukács a Merlau-Ponty", Löwy aponta para os representantes diretos do que ele chama de marxistas weberianos, a começar por Lukács, segundo o qual a racionalização capitalista faria com que todos os elementos presentes na sociedade fossem vistos como mercadorias passíveis de serem calculadas de forma racional, isto se estenderia às esferas da justiça e da administração, entre outras. Ou seja, Lukács justificaria o conceito de mercadoria a partir do desenvolvimento de uma racionalidade característica do capitalismo, ideia desenvolvida por Weber.

Seguindo essa linha, temos a escola de Frankfurt que empreenderia, segundo Löwy, uma ótica marxista tendo como pano de fundo uma concepção de história essencialmente weberiana, em que a formação do sistema capitalista e da sociedade moderna se deu a partir de um processo de racionalização que tornaria o Estado, a indústria e a cultura elementos puramente formais indiferentes à finalidade da ação dos indivíduos.

Outro autor abordado é Merlau-Ponty, que não só teria cunhado o termo marxismo weberiano, como também teria chamado a atenção para a necessidade de se pensar pelo método proposto por Weber, um marxismo menos dogmático, mas capaz de pensar políticas a partir das análises empreendidas numa crítica explícita, segundo Löwy, ao "marxismoleninismo" do Pravda e ao "ultrabolchevismo" de Sartre.

Enfim, o livro A jaula de aço: Max Weber e o marxismo weberiano 
proporciona pensar o terreno irregular de um "webero-marxismo" e, nesse sentido, possibilita, sobretudo, estabelecer um jogo entre dois cânones. Embora fique claro o pessimismo de Weber e o pensamento revolucionário dos marxistas explicitados na obra de Löwy, além de outras diferenças cruciais entre Marx e Weber, o livro de Löwy cumpre seu objetivo de fazer uma associação indispensável entre o que ele chama de o otimismo da vontade e o pessimismo da razão.

Glauber Miranda Florindo*

Recebido em

janeiro de 2015

Aprovado em

junho de 2016

* Glauber Miranda Florindo é Doutorando do Programa de Pós-Graduação em História da Universidade Federal Fluminense (UFF). E-mail: gmfhis@gmail.com. 